\title{
Impact of Introduction of Team Based Learning on Third Year MBBS Undergraduate Students
}

\author{
Manpreet Singh Nanda ${ }^{1}$, Rajdeep Singh ${ }^{2}$, Sonika Kotwal ${ }^{3}$ \\ 1,2,3 Department of ENT, Maharishi Markandeshwar Medical College and Hospital, \\ Solan, Himachal Pradesh, India.
}

\section{ABSTRACT}

\section{BACKGROUND}

There is a need for active learning in medical students. Team based learning is one of the active learning methods but relatively new to medical education. It promotes smaller groups within large class and team discussions which keeps every student involved and interested with requirement of less faculty. We wanted to study the impact and perception among third year undergraduate medical students with regard to team based learning in terms of interest, motivation, improvement in attendance and performance.

\section{METHODS}

A total of 10 team based learning sessions were held with initial lecture of 40 minutes and after few days a team based learning seminar of 2 hours duration was held. The various steps of team based learning seminar were pre class preparation, individual test, team test, team exercise, team presentation, facilitator clearing of doubts, awards and feedback. Attendance was monitored for each class. Students were divided into two groups of special learners and fast learners and performance of both groups in exams was analysed.

\section{RESULTS}

There was improvement in student attendance (86\% to $94 \%$ ) and student perception about team based learning as more and more seminars were held. Performance as a team during team based learning was better as compared to individual results. There was overall improvement in student performance in exams ( $47 \%$ to $59 \%$ ) which was more marked among special learners.

\section{CONCLUSIONS}

Team based learning is an effective method for large group learning as it is perceived better by students, makes them more interested, can help in understanding the topic better and incorporates team work ethics in them which in turn improves their performances, confidence and communication skills.

\section{KEY WORDS}

Attendance, Feedback, Lectures, Seminars, Team Based Learning
Corresponding Author:

Dr. Manpreet Singh Nanda,

H. No 554, Sector 36 B,

Chandigarh, India.

E-mail: drmsnfaimer@gmail.com

DOI: 10.14260/jemds/2020/794

How to Cite This Article:

Nanda MS, Singh R, Kotwal S, et al. Impact of introduction of team based learning on third year MBBS undergraduate students. J Evolution Med Dent Sci 2020;9(48):36133617, DOI: 10.14260/jemds/2020/794

Submission 20-08-2020,

Peer Review 14-10-2020,

Acceptance 20-10-2020,

Published 30-11-2020.

Copyright (C) 2020 Manpreet Singh Nanda et al. This is an open access article distributed under Creative Commons Attribution License [Attribution 4.0 International (CC BY 4.0)] 


\section{BACKGROUND}

Team Based Learning (TBL) though had been introduced in other professions, it is still relatively new to medical curriculum. ${ }^{1,2}$ In medical schools, mainly a lecture based or problem based strategies have been used.3,4 Medical education in our country is evolving a lot in past few years, so the teaching learning strategies too need to change accordingly. Lecture based learning has a limitation that it is a passive form of learning.5,6 Now a days a greater number of students are admitted in higher educational institutes, so bigger classes. Normal lectures and traditional seminars where few students are present, and the remaining class is a passive listener are unidirectional and not well taken. Above that most students prefer autonomy to guidance in education. ${ }^{7}$ Active learning is the need of the hour especially in adults where students decide their way of learning. For small groups a large number of faculty is required to initiate active learning. ${ }^{3}$

Team-based learning is a collaborative teaching learning strategy which is learner centred but instructor led. ${ }^{3}$ It is a form of small group learning within a large class that gives importance to student preparation before the class and application of knowledge in class. TBL promotes team discussions which keeps every student involved and interested. Here a single instructor can manage the whole large class subdivided into smaller groups and allows interactive learning without need for too many faculty. ${ }^{5}$ Hence, TBL involves a cycle that encompasses preparation, in-class readiness assurance testing, and an application-focused exercise. $^{2}$ Following individual answers, students work together to solve the answers and engage in collaborative learning. It is a well-known fact that teams outperform their own best member. ${ }^{8}$ team based learning focuses on team discussions and communication skills among team members. Here students learn more about benefits of team work. ${ }^{9}$

This strategy has not been so far introduced in our college. Previously we had traditional didactic lecture and traditional seminars where 5 students used to present the topic in front of the entire class of around 150 students where the most of remaining 145 students were not involved nor they were interested, so the process of active learning was not successful nor collaboration or teamwork or communication was possible.

We wanted to study the impact and perception of TBL among ENT undergraduate students by evaluating as to whether TBL improves student's interest in the topic and makes them more motivated, improves their performance when they work together as a team, and improves class attendance.

\section{METHODS}

This educational research study which is an evaluation study about teaching learning methods was introduced in a ENT class of $3^{\text {rd }}$ year undergraduate medical students after taking permission from Institutional Ethical Committee. After permission the faculty and students were sensitized to TBL by conducting sensitization lecture. Sensitization lecture was taken by the authors performing the study. This was a 1 hour session where the students were sensitized to TBL, its steps, the rules required to be followed and any clarifications of the students were clarified.

During each TBL session, one topic was covered in 2 hours 40 minutes ... 40 minutes of lecture and 2 hours of seminar. The students were given a topic and reading material in advance and they had to read and come, so that they can understand the topic better. The class was divided into smaller groups of 15 students each (roll number wise) and 10 groups were formed and the following steps of TBL were followed -

\section{Lecture}

This was taken in previous class for 40 minutes during which the facilitator explained the topics in brief covering the important aspects.

\section{Seminar}

This was held after a day or two after lecture. The components were

1. Pre-Class Preparation

Students read before class and the material was provided in form of articles, chapters, power point slides, videos and many more. So, this phase was - out of class.

\section{Individual Test}

Also called Individual Readiness Assurance Test (iRAT), each individual student had to answer few questions - 10 minutes.

\section{Team Test}

Also called Team Readiness Assurance Test (tRAT), the same test was performed as a team in their groups of 15 each - 10 minutes. The facilitators / investigators collected both and evaluated after class.

\section{Team Exercise}

Students in their groups had to discuss what team exercise regarding the questions they are going to perform, could be brief talk, debate, role plays - 20 minutes.

\section{Team Application}

The concepts understood were applied by team members in different scenarios and exercises were performed like interpretation, prediction and analysis as discussed earlier in team exercise - 5 minutes for each group - total 50 minutes.

\section{Clarification}

The instructor / facilitator clarifies on problematic questions to make the concepts clearer - 15 minutes.

\section{Closing Remarks, Feedback and Awards}

15 minutes. Feedback was taken by questionnaire which had open ended questions where the students were free to opine. Anonymity was maintained. The questionnaire was analysed by the authors conducting the study.

A total of 10 topics were covered by TBL (10 TBL sessions). The students were divided into two groups based on their performance in mid-term exams held in May 2019 (before 
initiating TBL) as special learners (score $<50 \%$ ) and fast learners (> $50 \%$ ). 70 students qualified as slow learners and 78 as fast learners. (Since $50 \%$ is the pass criteria in medical exams)

\section{Statistical Analysis}

The results were compared using mean / average, percentage (\%), Standard Deviation (SD), p value and $95 \%$ Confidence Interval. (CI)

\section{RESULTS}

Total 10 TBL sessions were held between the months of July to October 2019. Feedback was taken for TBL 1, 4 and 6 and 10. Attendance was monitored for each class. Student performance of both groups (fast and slow learners) during send up exams in November was analysed.

Regarding the attendance of students, there was improvement in attendance as compared to the earlier held pre TBL traditional seminars. The attendance improved as more and more TBL were held (Figure 1).

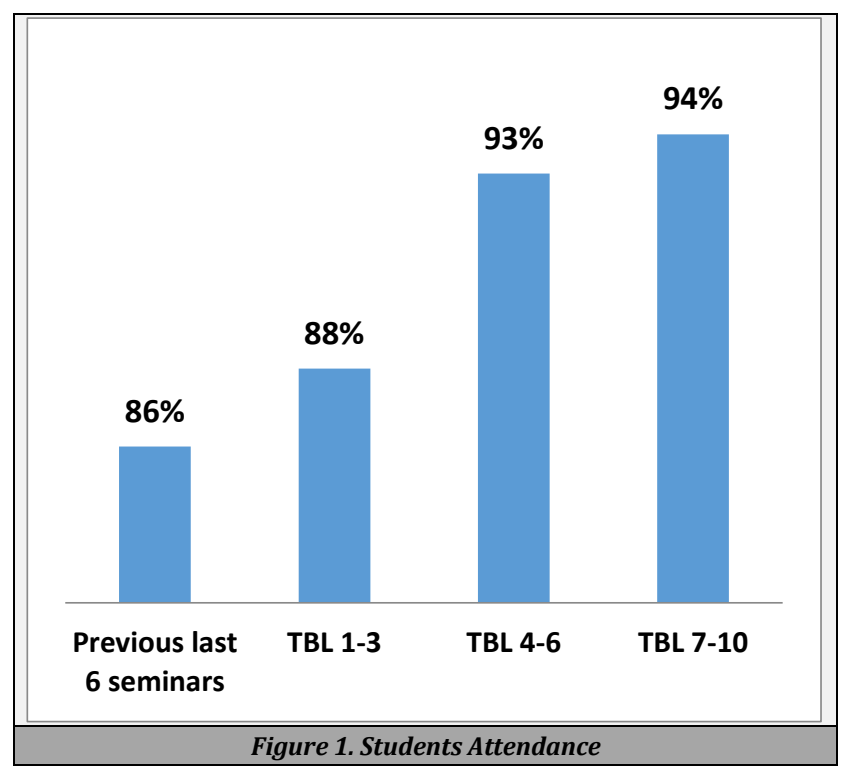

Regarding the feedback obtained from the students at the end of TBL 1, 4, 6 and 10, TBL improved the student's interest, motivation, and understanding of topic. There was marked improvement in student's perception about TBL sessions as more and more sessions were held (Table 1 ).

\begin{tabular}{|ccccc|}
\hline Measured Outcome & TBL-1 & TBL-4 & TBL-6 & TBL-10 \\
& $95 / 126$ & $114 / 134$ & $128 / 140$ & $131 / 142$ \\
Better interest among students & $(75 \%)$ & $(85 \%)$ & $(91 \%)$ & $(92 \%)$ \\
& $90 / 126$ & $112 / 134$ & $127 / 140$ & $131 / 142$ \\
Better motivation among students & $(71 \%)$ & $(84 \%)$ & $(90 \%)$ & $(92 \%)$ \\
Better understanding of topic & $94 / 126$ & $114 / 134$ & $128 / 140$ & $133 / 142$ \\
& $(74 \%)$ & $(85 \%)$ & $(91 \%)$ & $(93 \%)$ \\
If TBL better than traditional seminars & $80 / 126$ & $95 / 134$ & $120 / 140$ & $126 / 142$ \\
Whether students want more TBL & $(64 \%)$ & $(71 \%)$ & $(86 \%)$ & $(89 \%)$ \\
seminars in future & $(70 \%)$ & $99 / 134$ & $126 / 140$ & $130 / 142$ \\
Table 1. Feedback Questionnaire Outcomes & $(90 \%)$ & $(91 \%)$ \\
\hline \multicolumn{5}{c}{ Tabo } \\
\hline
\end{tabular}

Regarding the comparison of iRAT and tRAT scores, the performance as a team was better than individual best performance in the group of 15 each. The results were found to be statistically significant (Table 2).

\begin{tabular}{|ccc|}
\hline TBL & $\begin{array}{c}\text { Average Best } \\
\text { iRAT Score } \\
\text { (max-10) }\end{array}$ & $\begin{array}{c}\text { Average tRAT } \\
\text { Score (max-10) }\end{array}$ \\
TBL-1 & $6.7+/-0.5$ & $7.4+/-0.6$ \\
TBL-2 & $8.0+/-0.7$ & $8.6+/-0.6$ \\
TBL-3 & $7.2+/-0.7$ & $8.4+/-0.4$ \\
TBL-4 & $6.3+/-0.4$ & $7.8+/-0.4$ \\
TBL-5 & $7.9+/-0.8$ & $9.2+/-0.5$ \\
TBL-6 & $8.4+/-0.6$ & $9.3+/-0.6$ \\
TBL-7 & $7.5+/-0.7$ & $8.4+/-0.4$ \\
TBL-8 & $6.3+/-0.5$ & $7.9+/-0.5$ \\
\hline TBL-9 & $7.8+/-0.7$ & $8.3+/-0.4$ \\
TBL-10 & $8.1+/-0.4$ & $8.9+/-0.4$ \\
\hline Overall average & $7.5+/-0.6$ & $8.4+/-0.4$ \\
(mean + - SD) & & \\
\hline \multicolumn{2}{c}{ Table 2. Comparison of Individual and Team Scores } \\
\hline
\end{tabular}

(Note $-\mathrm{x} / \mathrm{y}(\%)-\mathrm{x}$ denotes number of students who opined that way, $y$ denotes total number of students who attended seminar, \% denotes percentage of total students who attended seminar and opined that way).

The students' performance improved from mid-term examination held before TBL to examination held after TBL. Special learners benefitted the most. The papers of the both exams were set by the same examiners with similar difficulty level (Table 3).

\begin{tabular}{|ccc|}
\hline & Mid-Term Examination & Send-Up Examination \\
\hline Special learners & $34.6 \%+/-5.2$ & $48.9 \%+/-4.8$ \\
Fast learners & $61.1 \%+/-6.0$ & $66.4 \%+/-5.0$ \\
Overall & $47.3 \%+/-5.8$ & $59.1 \%+/-4.8$ \\
\hline \multicolumn{2}{|c|}{ P Value $=<0.0001,95 \% \mathrm{CI}=10.5903$ to 13.0097} \\
\hline \multicolumn{2}{|c|}{ Table 3. Student Performance (Average $\%$ of Marks in Exams) } \\
\hline
\end{tabular}

\section{DISCUSSION}

A total of 10 TBL sessions were held and student's feedback was taken. For team exercises, the best performing groups were awarded. All students actively participated in the study. Pre TBL session was held where the whole process was explained and students were introduced to TBl.

We found better students perception of TBL in terms of attendance, student's interest, understanding of topic and desire to continue this method in future. Similar results were obtained by Wiener et al in 2009, who found that TBL was highly appreciated by the students. ${ }^{5}$ Though this exercise was time consuming, but it was acceptable among the students. Feedback was also taken through WhatsApp and those feedbacks were really encouraging. Most of the students appreciated and welcomed this new teaching learning method. Since, WhatsApp is in today's world the major mode of communication and very popular among youngsters, we chose this method. We could engage a large number of students through TBL by dividing them into smaller groups. This enabled active learning process which is the need of hour for adults. Similar results were obtained by researchers in Vienna where a large class of $1^{\text {st }}$ year medical students could be engaged through TBL. ${ }^{10}$ 
If we compare the individual best and team average scores for each TBL seminar, there was significant improvement in the scores when as a team as compared to the top individual scorer. In a study by Michaelson et al, the average team scores were $10 \%$ higher than the best performing individual scores. ${ }^{9}$ According to another study by Watson et al, when students work as a team, the results are always better. ${ }^{11}$ We also found that the perception improved among students as more TBL sessions were held. Similar results were obtained by Plass et al in 2004. ${ }^{7}$ Weiner et al also obtained similar results were initially the students were uncomfortable with TBL approach. ${ }^{5}$

We also found improvement in overall performance of students. Similar results of improved performance were obtained by Letassy et al among pharmacy students ${ }^{12}$ and Levine et al among psychiatry students. ${ }^{13}$ In our study the great impact of improvement in performance was seen among special learners. Similar results were obtained by Nieder et al who found more improvement in academically weaker students. ${ }^{14}$ Koles et al in 2010 also obtained better results in lower achieving students as compared to higher achieving students. ${ }^{2}$ Learners with special needs benefitted the most. These students mostly benefitted from their peers and learning together brought them interest in the topic and they could be engaged in a better way.

The only limitation of the TBL seminars was that it took more time as compared to traditional seminars but that was well accepted by the students, considering the benefits. It required better time management from the faculty. After successfully conducting the above, attempts will be made to get the TBL sessions implemented in the curriculum of the medical college. The faculty too will feel encouraged seeing their students showing interest and actively involved and performing better in the assessment exams.

The limitation of our study was that the perception of TBL among other teachers was not studied. Another limitation was our study only included MBBS students. Other courses students were not part of the study. In today's evolving health education more emphasis is being laid on inter disciplinary collaboration where students from various disciplines can study together. This is the need of hour as if they learn together, they can work together more effectively after completing their degrees and they can understand each other's role and responsibilities better. This will reduce medical errors in health care organisations and improve the patient care and patient satisfaction. TBL can contribute in this aim as it involves active learning with many collaborating together to learn. TBL also promotes leadership qualities among the students which makes them more confident and more successful.

It was an excellent learning experience for us as teachers. It was really encouraging how well the students perceived it, kind of energy and enthusiasm they showed during these sessions and the positive feedback we got from the students. The kind of role plays they did as team exercise with excellent coordination encourages us to use this TBL as a method of learning in future to achieve our goal of more competent Indian medical graduate. This will in turn help our society achieve the goal of better patient care and better health status of our citizens.

\section{CONCLUSIONS}

TBL is an effective method for large group learning as it is perceived to be better by students, makes them more interested, can understand the topic better and can incorporate the team work ethics in them which will in turn improve their performances, confidence and communication skills.

In future more studies will be taken in this field regarding effectiveness of TBL in interdisciplinary group where similar study will be done among students belonging to different health courses studying together. Also, the perception of TBL among other teachers will be studied in future studies.

Data sharing statement provided by the authors is available with the full text of this article at jemds.com.

Financial or other competing interests: None.

Disclosure forms provided by the authors are available with the full text of this article at jemds.com.

\section{REFERENCES}

[1] Dinan FJ, Frydrychowski VA. A team learning method for organic chemistry. J Chem Educ 1995;72(5):429-31.

[2] Koles PG, Stolfi A, Borges NJ, et al. The impact of teambased learning on medical students' academic performance. Acad Med 2010;85(11):1739-45.

[3] Parmelee DX, DeStephen D, Borges NJ. Medical students' attitude about team based learning in a pre- clinical curriculum. Med Educ Online 2009;14:1.

[4] Seidel CL, Richards BF. Application of team learning in a medical physiology course. Acad Med 2001;76(5):533-4.

[5] Weiner H, Plass H, Marz R. Team- based learning in intensive course format for first- year medical students. Croat Med J 2009;50(1):69-76.

[6] Nandi PL, Chan JNF, Chan CPK, et al. Undergraduate medical education: comparison of problem- based learning and conventional teaching. Hong Kong Med J 2000;6(3):301-6.

[7] Plass $\mathrm{H}$, Wiener $\mathrm{H}$, Kremser $\mathrm{K}$, et al. Team learning as a novel component of the new Vienna medical curriculum. Zeitschrift für Hochschuldidaktik 2004;5:31.

[8] Searle NS, Haidet P, Kelly PA, et al. Team learning in medical education: initial experiences at ten institutions. Acad Med 2003;78(10 Suppl):S55-8.

[9] Michaelsen LK, Watson WE, Black RH. A realistic test of individual versus group consensus decision making. J Appl Psychol 1989;74(5):834-9.

[10] Frischenschlager 0, Haidinger G, Mitterauer L. Factors associated with academic success at Vienna medical school: prospective survey. Croat Med J 2005;46(1):5865.

[11] Watson WE, Michaelsen LK, Sharp W. Member competence, group interaction and group decisionmaking: a longitudinal study. J Appl Psychol 1991;76(6):803-9.

[12] Letassy NA, Fugate SE, Medina MS, et al. Using team-based learning in an endocrine module taught across two campuses. Am J Pharm Educ 2008;72(5):103. 
[13] Levine RE, O'Boyle M, Haidet $\mathrm{P}$, et al. Transforming a clinical clerkship with team learning. Teach Learn Med 2004;16(3):270 -5.
[14] Nieder GL, Parmelee DX, Stolfi A, et al. Team-based learning in a medical gross anatomy and embryology course. Clin Anat 2005;18(1):56-63. 